\section{Aggregation in Cellular Slime Moulds : in vitro Isolation of Acrasin}

IN Dictyostelium and Polysphondylium, members of the Acrasiex, there is an aggregation stage in which previously independent amoboid cells stream towards certain cell clumps, which thus act as collecting centres, and there form communal fruiting bodies ${ }^{1}$. Communication between the centres and the reacting cells is through the external medium. Bonner ${ }^{2}$ produced indirect evidence that a chemical diffused outwards from the centres, setting up a concentration gradient by which the separate cells oriented themselves; pointing out that isolation in vitro would be the final proof of the chemical's existence, he named it 'acrasin'.

Pfützner-Eckert ${ }^{3}$ claimed that sensitive amobæ of D. mucoroides would move towards a cell-free block of agar on which centres had rested. My own repeated attempts to get orientation to an artificial gradient set up by such an agar block, or by drops of water which had bathed centres and then been absorbed on agar or sucked up a capillary tube, were unsuccessful. Theoretical arguments and experimental observations both suggested that acrasin was short-lived, the active molecules probably having a mean life of a few minutes. If this were so, it would be necessary to renew the head of an artificial gradient at frequent intervals in order to demonstrate orientation. This was finally achieved by sandwiching amœbæ between an agar block and a glass slide; drop by drop, washings from living centres were then rapidly and continually transferred to the meniscus around the block, whence the acrasin they contained diffused into the interior. Chemotaxis now occurred, sensitive cells moving not towards a point, as in normal aggregation, but parallel to each other towards the nearest edge.

To study the stability of acrasin, the washings were kept for short periods before adding them to the meniscus : if kept I min., attraction was strong; if 5 min., weak ; if 15 min., absent. The washings unavoidably contained a few loose cells from the centres, and there was scarcely sufficient time to remove them by centrifuging; but the fact that the reacting amobæ, unless they had formed an autonomous organization, became disoriented immediately I stopped adding washings to the meniscus made it unlikely that loose cells which had been carried over were playing any part in setting up the gradient. It was later found that if the washings were frozen within a few seconds of collection their activity was retained indefinitely, though lost as rapidly as before when they were returned to room temperature. No viable cells survived severe freezing.

A test for the presence of acrasin and a means of preserving it made possible a wide variety of experiments. Studies were made of conditions under which acrasin was secreted; the changes in sensitivity of reacting amcebæ; and the rate of decay of acrasin at different temperatures. No evidence could be obtained that acrasin was stored in centres.

As two mixed species of Dictyostelium form joint aggregations, whereas when Dictyostelium is grown with Polysphondylium each genus forms its own 4 , it might be expected that acrasin would be genusspecific. I examined $D$. discoideum, $D$. mucoroides, $D$. giganteum, $D$. purpureum and $P$. violaceum. Dictyostelium amœbæ of any species responded, as expected, to washings obtained from any Dictyostelium centre; but they also oriented themselves to wash- ings from $P$. centres. This seemed to indicate that acrasin was not specific; but further work showed that specific Polysphondylium - and Dictyosteliumacrasins, which oriented the corresponding cells, did in fact exist. Young $P$. centres and streams made only $P$-acrasin and attracted only $P$. cells. At a certain stage of development, $P$. centres began to make $D$-acrasin too and then attracted both $P$. and $D$. cells; for technical reasons, only centres of this later stage could be bathed to yield acrasin solution, and this oriented both cell types. $D$. centres did not attract $P$. cells, except old ones at short range ; probably $D$. centres made only $D$-acrasin, which had a weak effect on specially sensitive $P$. cells. The behaviour of $P$. centres was remarkable, for as they began to make $D$-acrasin their production of $P$-acrasin fell off; that is, they manufactured a foreign chemical, to which most $P$. cells were chemotactically insensitive, apparently at the expense of their own. It may be that $D$-acrasin takes some other role, as yet unknown, in both genera; whatever the explanation, the distribution of sensitivities and powers of synthesis suggest that Polysphondylium evolved from Dictyostelium; this is consistent with the morphological evidence.

Sussman and Noël ${ }^{5}$, and Sussman ${ }^{6}$, have shown that initiation of aggregation is a special process, and this confirms my own views based on quite different evidence. Once it is recognized that different acrasins are made at different stages of development, the possibility must be considered that some initiation factors are further slight modifications of the basic acrasin molecule.

\section{Department of Zoology,}

\section{B. M. SHAFFER}

\section{University, Cambridge.}

${ }^{1}$ Olive, E. W., Proc. Boston Soc. Nat. Hist., 30, 451 (1902).

a Bonner, J. T., J. Exp. Zool., 106, 1 (1947).

${ }^{3}$ Pfützner-Eckert, R., Archiv Entwicklungsmechanik, 144, 381 (1950).

4 Raper, K. B., and Thom, C., Amer. J. Bot., 28, 69 (1941).

${ }^{5}$ Sussman, M., and Noël, E., Biol. Bull., 103, 259 (1952).

- Sussman, M., Biol. Bull., 103, 446 (1952).

\section{Intolerance of Dizygotic Twin Lambs to Skin Homografts}

IT has been shown that homografts exchanged between dizygous cattle twins may often survive indefinitely in spite of the fact that grafts exchanged between full siblings other than twins, or between calves and dam, have not been found to survive more than twenty days after transplantation ${ }^{\mathbf{1 2}}$. This anomalous tolerance on the part of dizygous cattle twins is thought to have the same origin as their conformity of red-cell agglutination types ${ }^{3,4}$, namely, the confluence of their foetal circulations. The purpose of the present inquiry was to determine whether dizygous sheep twins are also tolerant to grafts of each other's skin.

The same methods were used as have been described for cattle ${ }^{2}$. Pinch grafts were taken from the shaved dorsal surface of the ear and fitted into recesses cut to receive them in a shaved area of the animal's side, just below the withers. The grafts were covered with tulle gras, a layer of sterile gauze and a pad of cotton wool. These dressings were held in place by a 'Lastonet' bandage which completely surrounded the animal. The bandage was secured by rubber latex solution ('Copydex') and Michel suture clips. With cattle, a hessian covering is used for protecting the bandage; 